Marquette University
e-Publications@Marquette

Electrical and Computer Engineering Faculty Research and Publications

Electrical and Computer Engineering,

\title{
$4-2013$
}

\section{Using Micro-Raman Spectroscopy to Assess MEMS Si/SiO2 Membranes Exhibiting Negative Spring Constant Behavior}

\author{
Lavern A. Starman \\ Air Force Institute of Technology \\ Ronald A. Coutu Jr. \\ Marquette University, ronald.coutu@marquette.edu
}

Follow this and additional works at: https://epublications.marquette.edu/electric_fac

Part of the Computer Engineering Commons, and the Electrical and Computer Engineering Commons

\section{Recommended Citation}

Starman, Lavern A. and Coutu, Ronald A. Jr., "Using Micro-Raman Spectroscopy to Assess MEMS Si/SiO2 Membranes Exhibiting Negative Spring Constant Behavior" (2013). Electrical and Computer Engineering Faculty Research and Publications. 360.

https://epublications.marquette.edu/electric_fac/360 
Marquette University

\section{e-Publications@Marquette}

\section{Electrical and Computer Engineering Faculty Research and Publications/College of Engineering}

This paper is NOT THE PUBLISHED VERSION; but the author's final, peer-reviewed manuscript. The published version may be accessed by following the link in the citation below.

Experimental Mechanics, Vol. 53, No. 4, (April, 2013): 593-604. DOI. This article is (C) Springer and permission has been granted for this version to appear in e-Publications@Marquette. Springer does not grant permission for this article to be further copied/distributed or hosted elsewhere without the express permission from Springer.

\section{Contents}

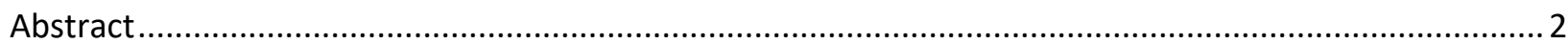

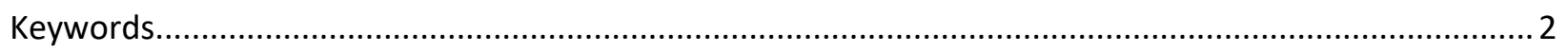

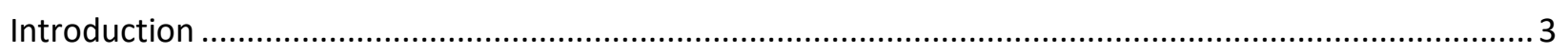

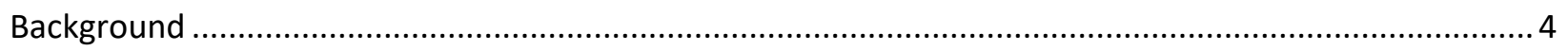

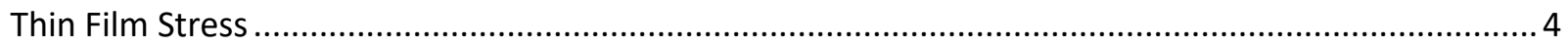

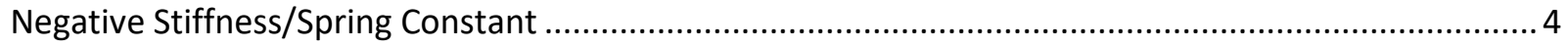

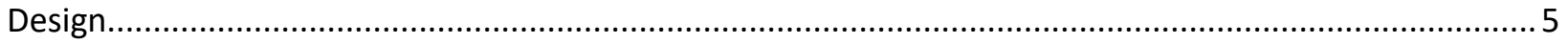

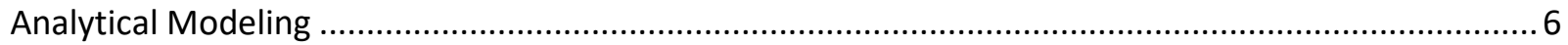

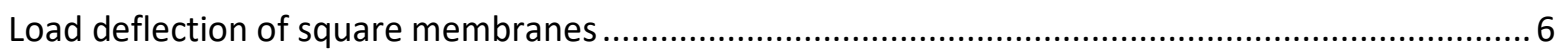

Uniform load fixed-fixed beam stress profile .............................................................................. 7

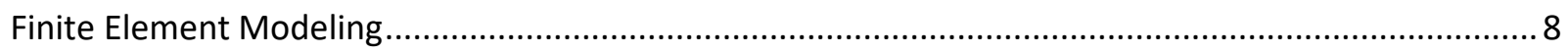

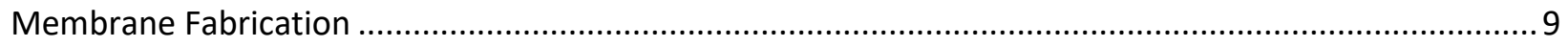

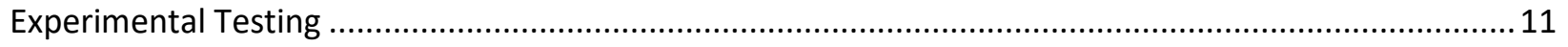

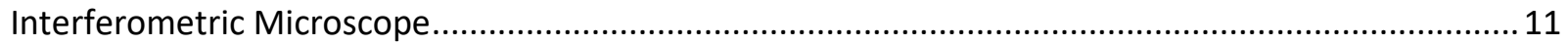

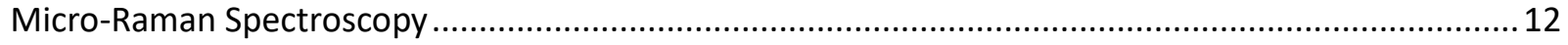

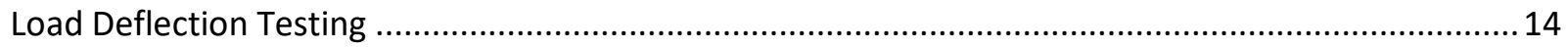

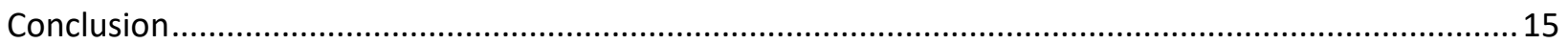


Notes

Acknowledgements. .16

References 16

\section{Using Micro-Raman Spectroscopy to Assess MEMS Si/SiO ${ }_{2}$ Membranes Exhibiting Negative Spring Constant Behavior}

\section{A. Starman}

Air Force Institute of Technology, Wright-Patterson Air Force Base, $\mathrm{OH}$

R. A. Coutu Jr.

Air Force Institute of Technology, Wright-Patterson Air Force Base, OH

\section{Abstract}

We introduce a novel micro-mechanical structure that exhibits two regions of stable linear positive and negative stiffness. Springs, cantilevers, beams and any other geometry that display an increasing return force that is proportional to the displacement can be considered to have a "Hookean" positive spring constant, or stiffness. Less well known is the opposite characteristic of a reducing return force for a given deflection, or negative stiffness. Unfortunately many simple negative stiffness structures exhibit unstable buckling and require additional moving components during deflection to avoid deforming out of its useful shape. In Micro-Electro-Mechanical Systems (MEMS) devices, buckling caused by stress at the interface of silicon and thermally grown $\mathrm{SiO}_{2}$ causes tensile and compressive forces that will warp structures if the silicon layer is thin enough. The $1 \mathrm{~mm}^{2}$ membrane structures presented here utilizes this effect but overcome this limitation and empirically demonstrates linearity in both regions. The $\mathrm{Si} / \mathrm{SiO}_{2}$ membranes presented deflect $\sim 17 \mu \mathrm{m}$ from their pre-released position. The load deflection curves produced exhibit positive linear stiffness with an inflection point holding nearly constant with a slight negative stiffness. Depositing a $0.05 \mu \mathrm{m}$ titanium and $0.3 \mu \mathrm{m}$ layer of gold on top of the $\mathrm{Si} / \mathrm{SiO}_{2}$ membrane reduces the initial deflection to $\sim 13.5 \mu \mathrm{m}$. However, the load deflection curve produced illustrates both a linear positive and negative spring constant with a fairly sharp inflection point. These results are potentially useful to selectively tune the spring constant of mechanical structures used in MEMS. The structures presented are manufactured using typical micromachining techniques and can be fabricated in-situ with other MEMS devices.

Keywords

Negative stiffness, Micro-Raman spectroscopy, Residual stress MEMS, Hookean 


\section{Introduction}

Numerous micro-mechanical devices such as cantilevers, beams, and springs display an increasing return force that is proportional to its displacement. Such devices can be considered to have a "Hookean" positive spring constant, or stiffness. While the opposite effect, a reducing return force for a given deflection is less well known, this effect has been in use for many decades. ${ }^{1}$ Stress at the interface of silicon and thermally grown silicon dioxide $\left(\mathrm{SiO}_{2}\right)$ is inherently unavoidable, and can cause buckling in Micro-Electro-Mechanical Systems (MEMS) devices. As the oxide forms on the surface of the silicon, the tendency for it to expand to its natural density is constrained by the interfacial bond and the oxide surrounding it. This causes tensile and compressive forces to develop which will warp structures if the silicon layer is relatively thin. The membrane structure presented here requires this deformation for proper operation. Simple cantilevers, beams and membrane structures operate through the use of potential energy being added to their systems as a result of structural displacement occurring. ${ }^{2,3}$ At some point in their deflection, the potential energy begins to aid in the deformation of the structure, reducing the force required for further displacement. Unstable systems can require moving constraints during deflection so as not to deform out of useful shape. Complex devices that mimic a negative linear stiffness are often used in large vibration isolation systems; ${ }^{-}$however, they are not practical on the MEMS scale. Recent MEMS research has attempted to use other methods to provide for negative stiffness, such as electrostatic forces. $\frac{5}{}$

In this paper, we introduce and characterize a novel micro-mechanical membrane structure that incorporates deformation due to the interfacial stresses between silicon and thermally grown $\mathrm{SiO}_{2}$ that empirically demonstrates similar spring return force characteristics of the disk cone spring shown in Fig. 1 (a). Several 16 element, $1 \mathrm{~mm}^{2}$ membranes were fabricated with a membrane composition consisting of a $5 \mu \mathrm{m}$ silicon layer and a $2 \mu \mathrm{m} \mathrm{SiO}$ layer. Figure 1 (b) shows the preliminary results for a typical $\mathrm{Si} / \mathrm{SiO}_{2}$ membrane fabricated using standard micromachining techniques which exhibits similar characteristics to the disk cone spring. ${ }^{-}$When adding a $0.35 \mu \mathrm{m}$ thin layer of titanium and gold to the membrane, the structure self constrains such that it exhibits stable linear positive and negative stiffness. These membrane structures are the first known devices to incorporate linearity in both regions. In addition, by limiting the deflection of the structure to only the negative stiffness region essentially creates the first linear negative stiffness micro-mechanical spring. Negative stiffness is potentially useful for selectively tuning the spring constant of micro-mechanical beams found in MEMS sensors and actuators.

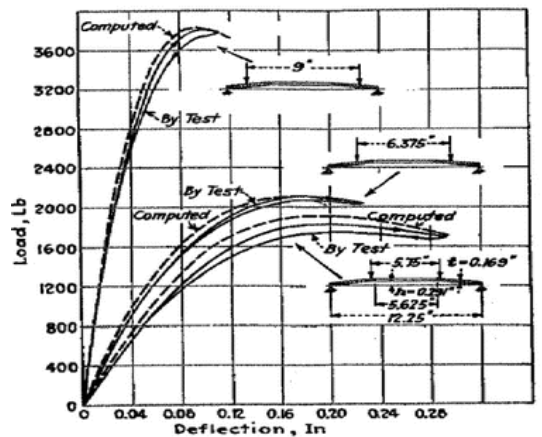

(a)

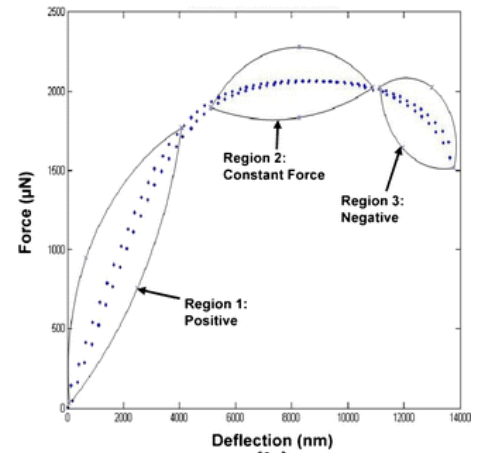

(b)

Fig. 1 (a) illustrates the load deflection plots for a macro scale center disk spring ${ }^{1}$ Reprinted with permission from J.O. Almen and A. Laszlo, Transactions of ASME Publications, Volume Number RP-58-10, 1936, and (b) shows the measured output load deflection for a micro-scale $\mathrm{Si}_{/} \mathrm{SiO}_{2}$ membrane from this research effort $\underline{\underline{6}}$ 


\section{Background}

A MEMS structure which exhibits similar load deflection characteristics as our $\mathrm{Si} / \mathrm{SiO}_{2} \mathrm{membrane}$ presented is the centrally clamped bistable silicon mechanism shown in Fig. 2(a)with its accompanying force vs. deflection plot shown in Fig. 2(b). ${ }^{7}$ The centrally-clamped device has a length of $3 \mathrm{~mm}$, a width of $10 \mu \mathrm{m}$ and a thickness of $480 \mu \mathrm{m} .{ }^{7}$ The device dimensions presented for our research are $1 \mathrm{~mm}^{2}$ membranes having a thickness of $\sim 7 \mu \mathrm{m}$. Although the structures are significantly different, the similarities in their operation can provide valuable insight into the overall operation of the fabricated $\mathrm{Si} / \mathrm{SiO}_{2}$ membranes.

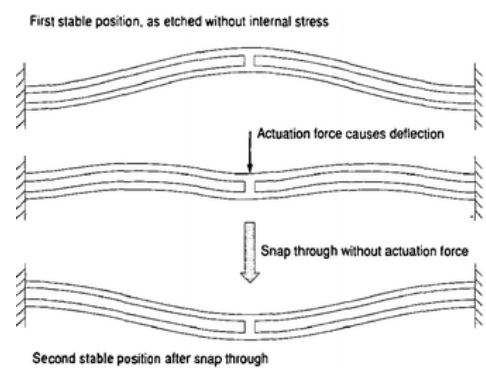

(a)

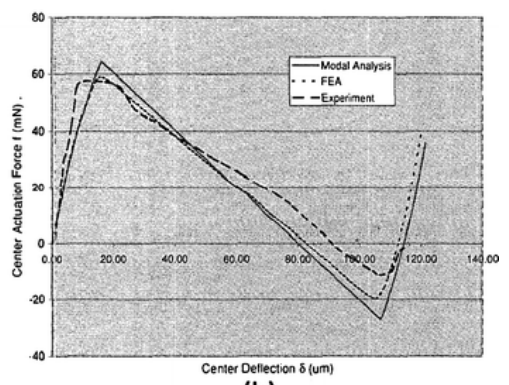

(b)

Fig. 2 (a) Fixed supported beam with center connection provides the load curves in (b) showing the linear region of deflection curve ${ }^{7}$ (C) 2001 IEEE, Reprinted, with permission, from IEEE Proceedings from the 14th IEEE International Conference on Micro Electro Mechanical Systems, MEMS 2001

\section{Thin Film Stress}

Stress develops in thin films due to a variety of reasons, including mismatched lattice constants, different coefficients of thermal expansion between materials, and as a result of the growth process [8] . Residual stress in thin films can influence dopant diffusion, affect hot carrier degradation and jeopardize oxide reliability. In MEMS, residual stress and residual stress gradients through the thickness of a film are critical constraints on microstructure designs. If the average residual stress is compressive for example, micro-bridges buckle if longer than a critical length while stress gradients generate an internal bending moment that causes micro devices to warp (up or down) out-of-plane upon release. ${ }^{9}$ Residual stress has a significant dependence on film thickness in which the highest compressive stress during deposition is created in the first $200 \mathrm{~nm}$ and begins to relax significantly if the film becomes thicker than $350 \mathrm{~nm} . \underline{10}$

\section{Negative Stiffness/Spring Constant}

Based on the parameters which make up the equation for the spring constant (equation ( $\underline{3})$ ), for a given material (fixed Young's Modulus), one can mechanically modify the spring constant by making physical changes in the geometry of the structure. $\underline{11}, \underline{12}, \underline{13}$ Some of these modifications could be impractical due to size constraints or they may exhibit undesirable displacement sensitivity effects. An alternative method to decrease the overall effective spring constant is to offset it with a negative stiffness.

Negative structural stiffness is fundamentally a reduction in return force for a given displacement. The mechanical realization of this concept has been used and studied for over 80 years.,$\underline{14}$ Many objects which demonstrate this are pre-strained, in a post-buckled state, require potential energy through preloading $\underline{\underline{15}}$ and can only produce it non-linearly. Dynamic modeling of these devices is generally constrained to small relative displacements so that linearization can be assumed allowing for easier 
design. Figure $\underline{3(a)}$ illustrates a simple spring system which demonstrates a typical theoretical load deflection plot shown in Fig. $\underline{3(b)}$ for a negative stiffness system.

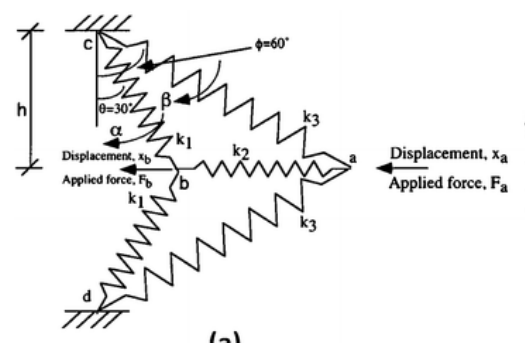

(a)

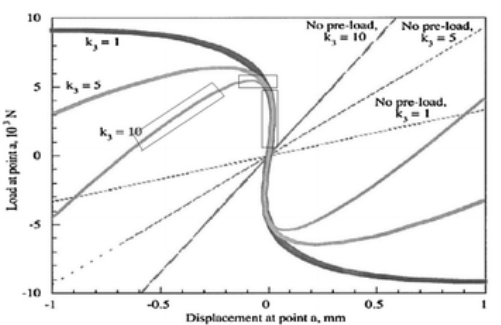

(b)

Fig. 3 (a) Equivalent resistive model of membrane, (b) load displacement curves of resistive model if point ' $a$ ' is restricted to only move in a horizontal plane. $\frac{15}{}$ Reprinted with permission from Y.C. Wang and R.S. Lakes, American Journal of Physics, Vol. 72, Page 40, 2004

Stiffness, also known as a spring constant, is the slope at any point in the plot. Initially, the $\mathrm{k}_{1}$ and $\mathrm{k}_{3}$ springs shown in Fig. $3(\mathrm{a})$ are in a non-loaded state with the upper and lower ends attached to fixed pivots (point's $c$ and d). The center spring $k_{2}$, is only free to move horizontally. As point ' $a$ ' in Fig. $\underline{3(a)}$ is deflected to the left, the $k_{1}, k_{2}$ and $k_{3}$ springs are compressed, forcing point ' $\mathrm{b}$ ' to also move to the left, such that potential energy is added to the system and the force increases to the right. This is demonstrated as the linear positive stiffness of $k_{3}=10$ shown in Fig. $\underline{3(b)}$. When the spring forces are in equilibrium around the midpoint, no force is produced right or left, and the system is at the unstable zero point as shown in Fig. $3(\mathrm{~b})$. Any additional deflection past this point results in the springs developing a force to the right and popping through as indicated by the spring values above the ' 0 ' displacement position in Fig. $\underline{3(b)}$. Negative stiffness is demonstrated after the inflection point up to the zero point. All key regions of the spring force are illustrated by rectangular boxes in Fig. $\underline{3(\mathrm{~b})}$ along the $k_{3}=10$ line.

Other research has concentrated on using active systems to produce a negative spring constant, such as with electrostatic forces. These systems of course require external power, and the development of effective control systems is ongoing. ${ }^{16}$ This research presents the results from the modification of a passive system, the buckled oxide membrane.

\section{Design}

The electrical operation of many MEMS devices can depend on spatial changes between surfaces or even the bending of materials which in turn change their electrical properties. Small changes in distances can easily be detected through capacitive sensing circuits and the flexing of piezoresistive materials can be measured through changes in electrical potential. For example, the displacement of a fixed-fixed beam, where the applied force is a point load at the center of the beam's length is given by $\underline{\underline{17}}$

$$
y=\frac{F L^{3}}{192 E I}(1)
$$

where, $F$ is the applied force, $L$ is the length of the beam, $E$ is the Young's Modulus of the beam material and $I$ is the moment of inertia. If we only consider rectangular structures, the moment of inertia is given by 


$$
I=\frac{w t^{3}}{12}(2)
$$

in which $w$ is the width of the beam and $t$ is the thickness of the beam with the bending moment about the $\mathrm{x}$-axis. The spring constant is determined from Hooke's Law $k=F / y$ where, $F$ is the applied force and $y$ is the displacement. $\frac{17}{17}$ The spring constant for a fixed-fixed beam can be determined by applying Hooke's law to equation (1) and then solving for the spring constant $k$.

$$
k=\frac{16 E w t^{3}}{L^{3}}(3)
$$

When we evaluate MEMS inertial sensors, these devices typically use a suspended mass which is attached by tethers to the surrounding bulk material to enable small, measurable displacements. $\frac{18}{\text { This }}$ displacement can be viewed similarly to the fixed-fixed beam described above in which the suspended mass acts as the point load force with the tethers being modeled as the beam. Therefore, the tether's thickness, length, shape and the material used all determine the required spring constant for displacement sensitivity and the resonant frequency as shown in equations (ㄴ) and (ㅁ)

$$
\begin{aligned}
S_{d} & =\frac{m a}{k}(4) \\
f_{\text {res }} & =\frac{\pi}{2} \sqrt{\frac{k}{m}}(5)
\end{aligned}
$$

where, $a$ is the acceleration, $m$ is the mass and $k$ is the spring constant. As shown in the above equations, both the mass and the spring constant inversely affect the sensitivity and resonant frequency. For example, if the mass is increased, the sensitivity increases; however, the resonant frequency decreases. The opposite effect is true if the spring constant is changed. Therefore, since a change in mass has opposing effects on the sensitivity and resonance, the mass will be considered a constant in this research. This assumption allows us to focus on the spring constant variable which is the focal point of this paper.

\section{Analytical Modeling}

To quantify the deflection of the $\mathrm{Si} / \mathrm{SiO}_{2}$ membrane following the deep reactive ion etch, two different models will be used. Since our fabricated structure is a square membrane, the first model consists of a load deflection of square membranes. The second model will access the stress within the membrane as a uniform load on a fixed-fixed microbridge. This stress model will aid in the characterization of the stress profiles obtained from micro-Raman spectroscopy.

Load deflection of square membranes

Although the solutions for small deflection theory and membrane theory are well known, $, \underline{19}, \underline{20}, \underline{21}, \underline{22}$ the theory is briefly repeated here for completeness. For small deflections, thin film plate theory deflection is said to be dominated by the resistance of the membrane to bending. Tabata et al. $\frac{19}{}$ developed an analytical solution for the load-deflection relationship for rectangular membranes. This relationship between the external load and the membrane deflection makes it possible to determine the residual stress and Young's modulus of thin films. The load-deflection behavior is of the form 


$$
p=\frac{C_{1} \sigma t h}{d^{2}}+\frac{C_{2} E t h^{3}}{d^{4}}(6)
$$

where, $p$ is the applied pressure, $h$ is the center deflection, $d$ is one half of the membrane's edge length, $t$ is the membranes thickness, $E$ is the Young's modulus, $\sigma$ is the residual stress, and $v$ is the inplane Poisson's ratio. The values $C_{1}$ and $C_{2}$ are numerical constants which are determined by the membranes shape $b / a=1 / n$ where $a$ and $b$ are the length and width of the membrane which is used only to define the variable " $n$ ", thus for a square membrane such as our device presented, $(n=1)$. The constants $C_{1}$ and $C_{2}$ are derived from the following equations $\underline{\underline{19}}$

$$
C_{1}=\frac{\pi^{4}\left(1+n^{2}\right)}{64}(7)
$$

And

$$
C_{2}=\frac{\pi^{6}}{32\left(1-v^{2}\right)}\left\{\frac{9+2 n^{2}+9 n^{4}}{256}-\left[\frac{\left(4+n+n^{2}+4 n^{3}-3 n v(1+n)\right)^{2}}{2\left\{81 \pi^{2}\left(1+n^{2}\right)+128 n+v\left[128 n-9 \pi^{2}\left(1+n^{2}\right)\right]\right\}}\right]\right\}
$$

Maier-Schneider et al. $\underline{20}$ slightly modified the above equations to account for the real bending behavior of a silicon nitride membrane by taking into account the effects of Poisson's ratio and Young's modulus to obtain values for $C_{1}$ and $C_{2}$ to be 3.45 and 2.48 respectively. These values for $C_{1}$ and $C_{2}$ closely match finite element analysis (FEM) results determined by Pan et al. $\underline{21}$ for silicon nitride.

For the $\mathrm{Si} / \mathrm{SiO}_{2}$ membrane fabricated in this research effort, the constants $C_{1}$ and $C_{2}$ are analytically determined to be 3.04 and 1.83 respectively. These values for $C_{1}$ and $C_{2}$ are slightly different from the previous work by Maier-Schneider et al. $\frac{20}{}$ due to the different Poisson's ratio and Young's modulus for the $\mathrm{Si} / \mathrm{SiO}_{2}$ membrane verse the $\mathrm{SiN}$ membrane. Through interpolation from the membrane material properties, the residual stress is calculated to be $72.14 \mathrm{MPa}$ and Young's modulus is $110.71 \mathrm{GPa}$. By applying these values, the analytically derived applied pressure as determined from equation (6) is $0.149 \mathrm{MPa}$.

For the second membrane (i.e. titanium and gold layers added), the equivalent interpolated Poisson's ratio slightly increased to 0.255 , Young's modulus decreased slightly too approximately $109.42 \mathrm{GPa}$ and the residual stress increased to approximately $80.95 \mathrm{MPa}$. The constants $C_{1}$ and $C_{2}$ remain approximately the same while the applied pressure increased slightly too approximately $0.166 \mathrm{MPa}$. This slight increase is a result of the additional tensile stress in the thin metal layers deposited onto the membrane.

\section{Uniform load fixed-fixed beam stress profile}

An analytical microbridge beam stress profile was created to provide insight into the stress profile characteristics obtained using micro-Raman spectroscopy. This model was selected since a narrow fixedfixed beam could realistically replicate the stress profile for a square membrane. A narrow beam slice through the center and across the membrane will experience slight torsion and twisting effects; however, these effects will be minimal and not be considered in this model. This analytical solution provides insight into the residual stress profile for a freestanding microbridge beam. The analytical model uses a uniform distributed load $g$ as shown in Fig. $\underline{4(a)} . R_{1}$ and $R_{2}$ are the resultant forces, and $M_{1}$ and $M_{2}$ are the moments about the microbridge beam. $\underline{23}$ 


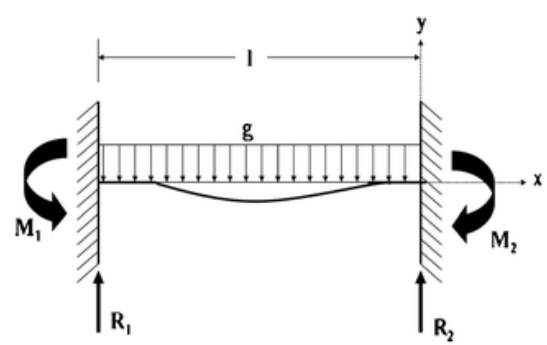

(a)

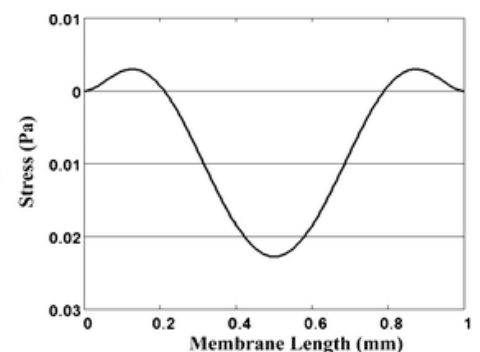

(b)

Fig. 4 (a) Analytical stress model for a MEMS microbridge beam assuming a uniform distributed load and (b) stress profile obtained for a small, distributed load $\underline{17}$

For a released microbridge beam with a uniform distributed load, the residual stress can be calculated by the following equation $\underline{23}$

$$
\sigma=\frac{M(x) y}{I}(P a)(9)
$$

where $M(x)$ is the moment about the beam and is given by $\underline{\underline{23}}$

$$
M(x)=\frac{g}{12}\left(6 l x-6 x^{2}-l^{2}\right)(N / m)(10)
$$

where $g$ is the distributed load, $l$ is the beam length, and $x$ is a selected position along the length of the beam respectively. For the analytical stress model calculation plotted in Fig. $\underline{4(\mathrm{~b})}$, the value of $x$ was stepped from 0 to $1000 \mu \mathrm{m}$ (model beam length). The compressive residual stress along the length of the beam can be assessed to be a uniform load since this stress will produce a constant, uniform applied force within the material layer. Although the stress magnitudes for this simplified model for the microbridge are small due to the minimal uniform load applied, the experimentally measured Raman stress profiles presented later for a released membrane clearly resembles the stress profile shown in Fig. $\underline{4(b)}$ for a microbridge beam.

The SOI wafer used in this research has a $2 \mu \mathrm{m}$ thick oxide layer with a $5 \mu \mathrm{m}$ thick silicon device layer. Once the deep reactive ion etch (DRIE) is complete, the $7 \mu \mathrm{m}$ thick membrane consisting of the oxide and the silicon device layer will deflect due to the inherent residual stresses. Thermally grown $\mathrm{SiO}_{2}$ residual stress values are approximately $300 \mathrm{MPa}$ compressive while the residual stress in the crystalline silicon device layer should be small due to minimal vacancies, interstitials, and stress gradients.

\section{Finite Element Modeling}

To assess the deflection of the $\mathrm{Si} / \mathrm{SiO}_{2}$ membrane following the DRIE, an FEM model was developed using CoventorWare ${ }^{24}$ to observe peak stress locations and membrane deflection magnitudes. The model consisted of a stacked $1 \mathrm{~mm}^{2} \mathrm{Si} / \mathrm{SiO}_{2}$ membrane in which all edges of the membrane are fixed in the $x$ - and $y$-directions such that deflection only occurs in the $z$-direction. A Manhattan brick mesh of $10 \times 10 \times 2 \mu \mathrm{m}$ was used for all $\mathrm{Si} / \mathrm{SiO}_{2}$ membrane simulations. From experimental membrane deflection results, the models internal stresses were set to obtain the approximate $17 \mu \mathrm{m}$ deflection of the released membrane. From De Wolf, $\underline{25}$ nearly all inherent residual stress in a $\mathrm{Si} / \mathrm{SiO}_{2}$ stacked material lies within the oxide layer. The silicon device layer has minimal stress due to its crystalline structure as stated by Best. $\frac{26}{6}$ The above statements by De Wolf and Best held true for this $\mathrm{Si} / \mathrm{SiO}_{2}$ membrane 
simulation in that the model required approximately $240 \mathrm{MPa}$ of compressive stress be integrated into the oxide material layer and $5 \mathrm{MPa}$ to the silicon layer to reach our $17 \mu \mathrm{m}$ measured deflection.

A second FEM model was developed to assess the effects the $500 \AA$ titanium and $3000 \AA$ gold layers have on the overall deflection and functionality of the $\mathrm{Si} / \mathrm{SiO}_{2}$ membrane. The material stress parameters for the silicon and oxide layers remained the same from the $\mathrm{Si} / \mathrm{SiO}_{2}$ membrane simulation. Due to the thin titanium layer's inability to be meshed with Manhattan Brick elements, a parabolic mesh was selected for all layers using an element size of $50 \mu \mathrm{m}$ to minimize simulation times. The residual stress values for the titanium and gold layers were set to be $65 \mathrm{MPa}$ and $25 \mathrm{MPa}$ respectively. Figure $5(\mathrm{a})$ shows an example 3D membrane deflection image obtained from CoventorWare for the $\mathrm{Si} / \mathrm{SiO}_{2}$ membrane and Fig. $\underline{5(\mathrm{~b})}$ provides a $2 \mathrm{D}$ profile comparing the peak deflections from the $\mathrm{Si} / \mathrm{SiO}_{2}$ membrane and the $\mathrm{Si} / \mathrm{SiO}_{2}$ membrane incorporating the Ti/Au metal layers. As shown in Fig. $\underline{5(b)}$ the displacement magnitude of the $\mathrm{Si} / \mathrm{SiO}_{2}$ membrane decreased from approximately $17 \mu \mathrm{m}$ to $13.5 \mu \mathrm{m}$ with the additional metal layers. This reduced deflection is a result of the added material thickness encompassing the membrane (i.e. $7 \mu \mathrm{m}$ to $7.35 \mu \mathrm{m}$ ), and the tensile stress of the metal layers. From theory, both the membrane thickness and the additional tensile stress should diminish the peak membrane deflection as the model illustrates.

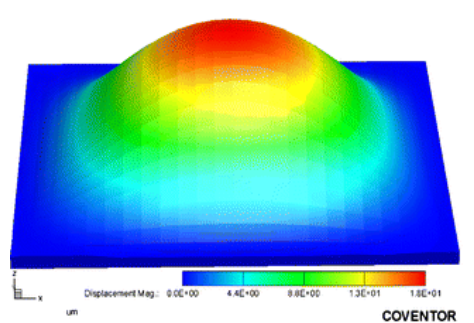

(a)

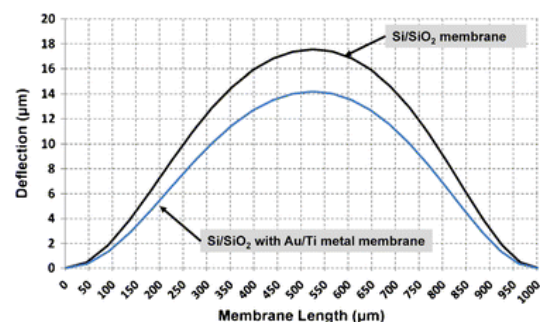

(b)

Fig. $5 \mathrm{FEM}$ membrane deflection image for (a) $3 \mathrm{D} \mathrm{Si} / \mathrm{SiO}_{2}$ stacked membrane illustrating the peak deflection magnitude and (b) shows a comparison of the deflection profiles for the $\mathrm{Si} / \mathrm{SiO}_{2}$ stacked membrane and the $\mathrm{Si} / \mathrm{SiO}_{2}$ stacked membrane with $\mathrm{Ti} / \mathrm{Au}$ metals. The added metal layer reduced the peak membrane deflection by $\sim 4 \mu \mathrm{m}$

\section{Membrane Fabrication}

The $\mathrm{Si} / \mathrm{SiO}_{2}$ membrane was fabricated using a Silicon-On-Insulator (SOI) wafer from Ultrasil Corporation. The membrane consists of a $2 \mu \mathrm{m}$ thick $\mathrm{SiO}_{2}$ layer thermally grown on the silicon substrate. A second wafer (device layer) is then bonded to the oxide and thinned via chemical mechanical polishing (CMP) to a thickness of $5 \mu \mathrm{m}$. Both the device and substrate layers were $n$-type, $<100>$ monocrystalline silicon with layer thicknesses of 5 and $400 \mu \mathrm{m}$ respectively. In addition to being a component material layer in the membrane, the $2 \mu \mathrm{m}$ buried oxide layer also served as a natural etch stop for the DRIE process. For this research effort, two different device membranes are fabricated; 1 ) a $\mathrm{Si} / \mathrm{SiO}_{2}$ membrane and, 2) a $\mathrm{Si} / \mathrm{SiO}_{2}$ membrane with the additional metal layer consisting of $500 \AA$ titanium/3000 $\AA$ gold. This metal layer was deposited on top of the device layer prior to the DRIE. Figure $\underline{6}$ shows an optical image of two elements of a 16 element $\mathrm{Si} / \mathrm{SiO}_{2}$ membrane with the additional Ti/Au metal layer. Figure $6(\mathrm{a})$ shows a top view of two elements while Fig. $\underline{6(b)}$ shows the same two elements as viewed from the backside of

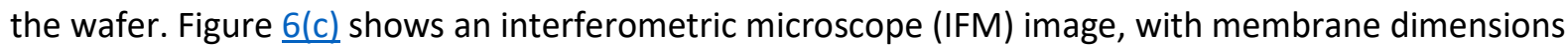
labeled, of the top of the membrane illustrating the inward deflection of the membrane as observed by the fringe lines identifying the edges of the membrane. 


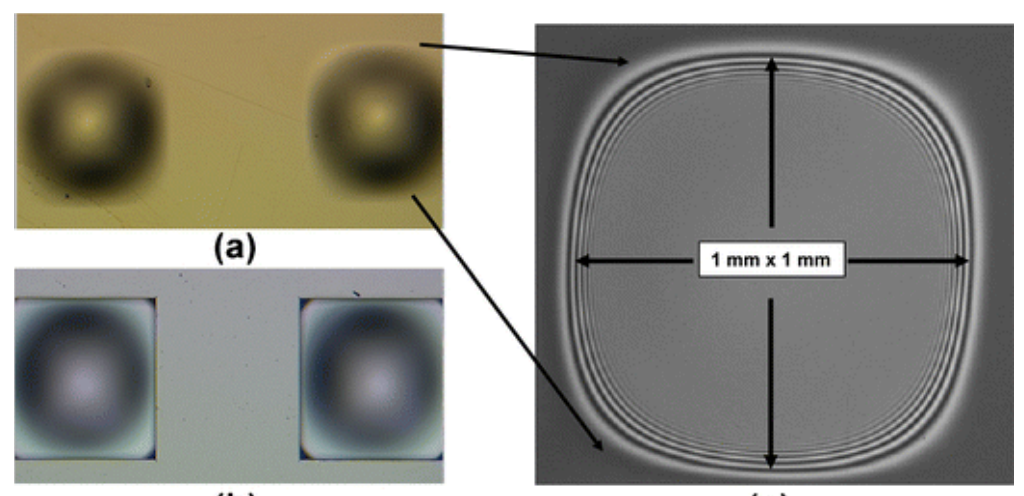

(b)

(c)

Fig. 6 Optical images of the fabricated $\mathrm{Si} / \mathrm{SiO}_{2}$ membrane with the Ti/Au metal layer. (a) a two element membrane image as observed from the top surface, (b) the same two element membrane as observed from the backside of the wafer showing the bottom side of the membrane, and (c) an IFM image illustrating the deflection of the membrane as observed by the optical fringe lines while showing the physical dimensions of the membrane

The backside wafer preparation began with the deposition of a $3 \mu \mathrm{m}$ plasma enhanced chemical vapor deposition (PECVD) $\mathrm{SiO}_{2}$ layer. A $2 \mu \mathrm{m}$ thick photoresist layer was used to pattern the PECVD oxide layer to define the backside of the square membranes. The patterned photoresist was developed to expose the oxide layer which was then etched using a buffered oxide etch (BOE). The patterned oxide now becomes a robust mask layer which is necessary for the lengthy silicon substrate DRIE etch. Lastly, the silicon substrate is etched through the backside window all the way to the buried topside oxide layer using a DRIE Bosch process. The cavity created enables the micro-Newton force sensor to be inserted into the $1 \mathrm{~mm}^{2}$ cavity to supply the desired force on the membrane.

The general fabrication process is identical for both membranes and is outlined in Fig. $\underline{7}$. The oxide layer, due to a different coefficient of thermal expansion than the crystalline silicon device layer, is under compressive stress and results in the $\mathrm{Si} / \mathrm{SiO}_{2}$ membrane buckling repeatedly inward once the handle layer is removed via the DRIE process. In an effort to develop a consistent, repeatable fabrication process, a series of 10 different fabrication runs were performed using a 16 element $\mathrm{Si} / \mathrm{SiO}_{2}$ membrane array to assess the fabrication process and verify device performance. In addition, five additional fabrication runs were performed using the same 16 element $\mathrm{Si} / \mathrm{SiO}_{2}$ membrane array with the $\mathrm{Ti} / \mathrm{Au}$ metal layer added to the membrane surface to verify device performance. Overall, the fabrication process is very repeatable for either membrane type with nearly identical post fabrication results. 
(a)

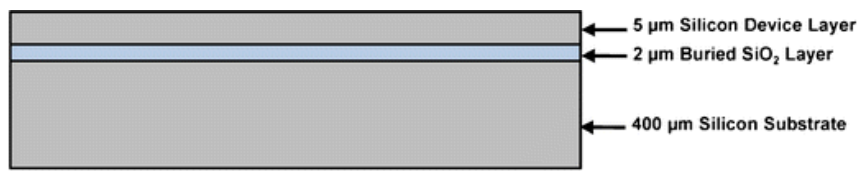

(b)

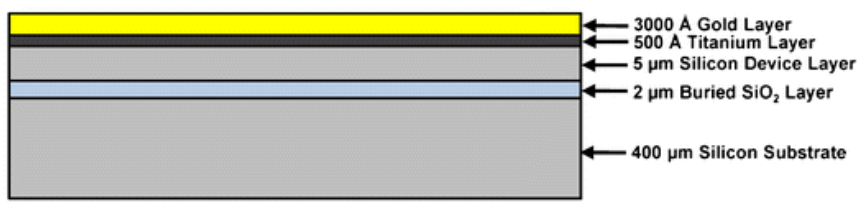

(c)

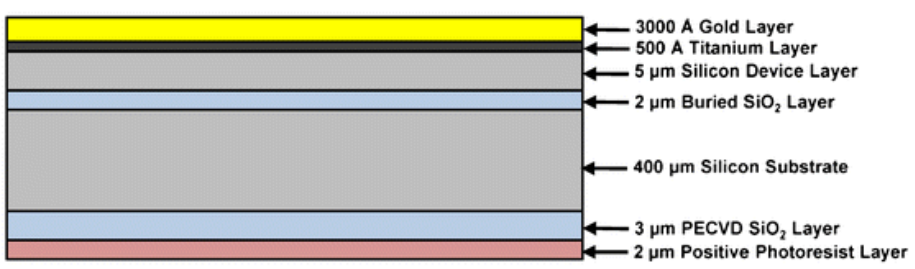

(d)

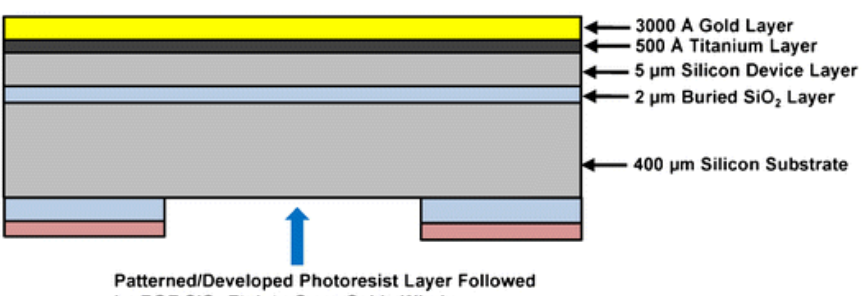

PatternediDeveloped Photoresist Layer Followed by $\mathrm{BOE} \mathrm{SiO}_{2}$ Etch to Open Oxide Window

(e)

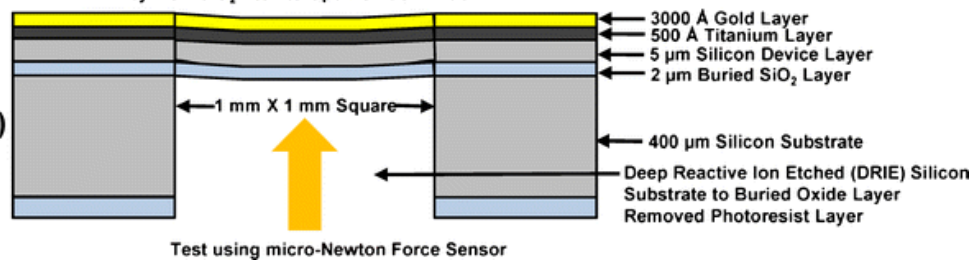

Fig. 7 Sequential fabrication of the multilayer material membrane, (a) illustrates the substrate wafer with a $2 \mu \mathrm{m}$ buried oxide layer with a $5 \mu \mathrm{m}$ Si device layer, (b) shows the evaporated metal layers ( $500 \AA \mathrm{Ti}, 3000 \AA$ gold), (c) backside wafer preparation beginning with a $3 \mu \mathrm{m} \mathrm{PECVD} \mathrm{SiO}_{2}$ layer followed by a $2 \mu \mathrm{m}$ thick photoresist layer for patterning, (d) Photoresist is patterned and developed to expose oxide layer which is then followed by a BOE etch to remove the oxide, and lastly, (e) the silicon substrate is DRIE through the backside window to the buried topside oxide layer, which acts as a natural etch stop. A micro-Newton force sensor is then inserted into the $1 \mathrm{~mm} \times 1 \mathrm{~mm}$ cavity to supply the desired force on the membrane

\section{Experimental Testing}

To test the operation of the $\mathrm{Si} / \mathrm{SiO}_{2}$ membrane and the $\mathrm{Si} / \mathrm{SiO}_{2} \mathrm{Ti} / \mathrm{Au}$ membrane, three different experimental testing procedures were performed. The first testing sequence involved the use of an IFM to measure the peak deflections of the various membranes. The second set of testing involved the use of micro-Raman spectroscopy to measure the stress within the $\mathrm{Si} / \mathrm{SiO}_{2} \mathrm{membrane}$. The final set of tests involved load deflection tests which used a micro-Newton force sensor to physically deflect the $\mathrm{Si} / \mathrm{SiO}_{2}$ and the $\mathrm{Si} / \mathrm{SiO}_{2} \mathrm{Ti} / \mathrm{Au}$ membranes to measure the spring constant for each membrane type. Each testing procedure is outlined below with associated results.

\section{Interferometric Microscope}

To verify the out of plane deflection of the released $\mathrm{Si} / \mathrm{SiO}_{2}$ membrane, an IFM was used to measure the peak deflection of the membranes. Figure $\underline{8(a)}$ illustrates a typical 2D deflection profile and Fig. $\underline{8(b)}$ illustrates a typical 3D deflection image for the membrane which represents an axially 
symmetric inverted dome. As shown in Fig. $\underline{8(\mathrm{c})}$, the $\mathrm{Si} / \mathrm{SiO}_{2}$ membrane has a peak deflection of approximately $17.0 \mu \mathrm{m}$. A second membrane consisting of $\mathrm{Si} / \mathrm{SiO}_{2}$ with the additional $\mathrm{Ti} / \mathrm{Au}$ metal on the

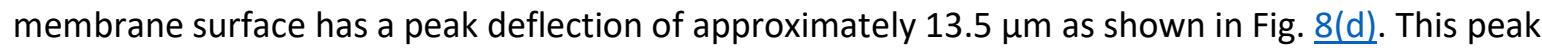
deflection reduction was expected based on the FEM analysis results obtained earlier. In general, the silicon device layer on top of the $2 \mu \mathrm{m}$ thick oxide layer should inhibit the out of plane deflection, meaning the membrane should deflect into the cavity created by the DRIE etch. This in-cavity deflection held true for all cases; however, when the fabrication of the membrane included the addition of the metal Ti/Au layer, the inward deflection magnitude was reduced. A series of $5 \mathrm{Si} / \mathrm{SiO}_{2}$ wafers and an additional $5 \mathrm{Si} / \mathrm{SiO}_{2}$ with $\mathrm{Ti} / \mathrm{Au}$ metal added on the device layer were fabricated. Each fabricated wafer consisted of the 16 element membrane array in which each membrane was measured using the IFM to determine the repeatability of the fabrication process as well as the consistency in membrane deflection. The average $\mathrm{Si} / \mathrm{SiO}_{2}$ membranes deflection measured $17.0 \pm 0.5 \mu \mathrm{m}$ while the $\mathrm{Si} / \mathrm{SiO}_{2}$ with the Ti/Au metal layer averaged approximately $13.5 \pm 0.3 \mu \mathrm{m}$.

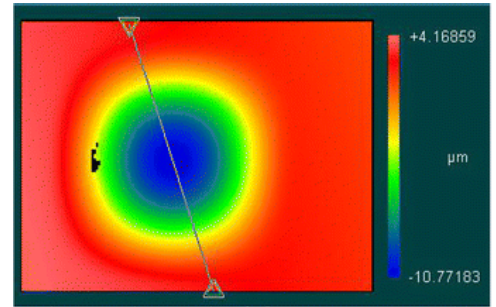

(a)

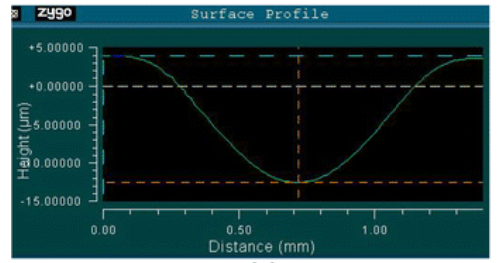

(c)

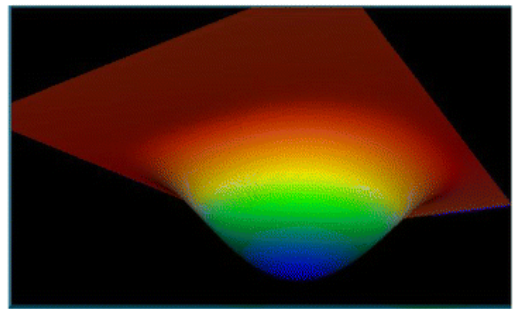

(b)

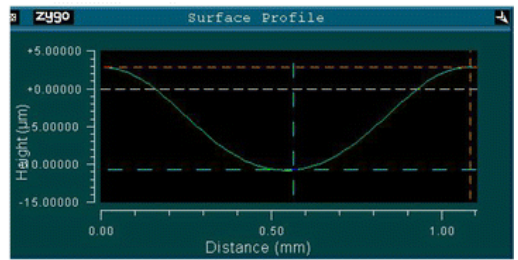

(d)

Fig. 8 IFM images illustrating the $\mathrm{Si} / \mathrm{SiO}_{2}$ membrane deflection upon release (a) provides the 2D image, (b) shows the 3D image of the membrane, (c) illustrates the $\sim 17 \mu \mathrm{m}$ deflection profile for the $\mathrm{Si} / \mathrm{SiO}_{2}$ membrane, and (d) illustrates the $\sim 13.5 \mu \mathrm{m}$ deflection profile for the $\mathrm{Si} / \mathrm{SiO}_{2}$ membrane with $\mathrm{Ti} / \mathrm{Au}$ metal

\section{Micro-Raman Spectroscopy}

The mechanical properties of structural layers, in particular the stress and stress gradients are very important for proper device performance. This research builds on the understanding and behavior of thin film silicon structures as their scaled down in size. Several techniques have been used to characterize the strain in silicon thin films to include wafer curvature, $\underline{\underline{27}}$ membrane load deflection, $\underline{28}$ interferometric measurements (IFM) of deflection and curvature and X-ray diffraction. $\underline{29}$ Previously, micro-Raman spectroscopy was used to measure residual and induced stresses in silicon MEMS structures..$\frac{30}{}$ Micro-Raman spectroscopy was selected since it has the advantage of being fast and nondestructive with micrometer spacial resolution. Several groups have shown micro-Raman spectroscopy is an effective technique for the measurement of mechanical stress in silicon $\underline{30}, \underline{31}, \underline{32}, \underline{33}, \underline{34}, \underline{35}, \underline{36}, \underline{37}, \underline{38}$ and silicon MEMS devices. $\underline{39}, \underline{40}, \underline{41}, \underline{42}, \underline{43}, \underline{44}, \underline{45}, \underline{46}$

In micro-Raman spectroscopy, laser light is focused on the sample through a microscope to a spot size of $\sim 1 \mu \mathrm{m}$ in diameter. A laser beam $(\lambda=532 \mathrm{~nm})$ is used to irradiate the sample and the scattered light, which carries the Raman signals, is collected and directed into a spectrometer. The spectrometer 
measures the intensity of the Raman signal as a function of frequency. For an unstressed sample, the spectrometer measures a reference spectrum. Figure 9(a) shows a typical Raman spectrum for silicon which is used in this study. The Rayleigh scattering (laser line) is used as a reference to locally and individually calibrate each Raman spectrum. When the sample is placed in a stressed state, the Raman spectrum displays a shift in frequency with respect to the reference spectrum as shown in Fig. 9(b). This frequency shift is a result of residual or induced stress.

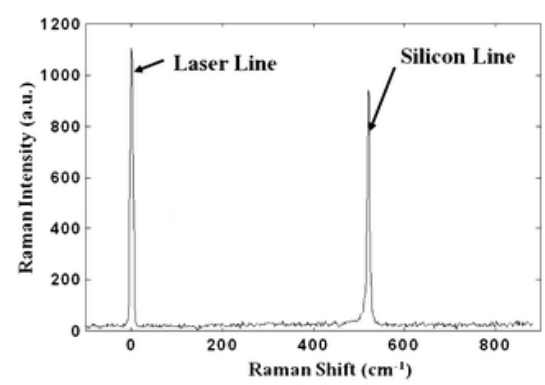

(a)

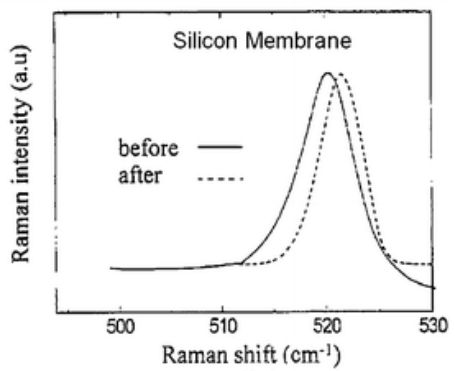

(b)

Fig. 9 (a) illustrates a typical Micro-Raman Spectroscopy profile for silicon showing both the Rayleigh (laser line) and the silicon line, and (b) illustrates a typical frequency shift due to stress in the silicon material

For this effort, micro-Raman spectroscopy was used to measure the residual stress in the released $\mathrm{Si} / \mathrm{SiO}_{2}$ membrane structure. The Raman spectra were obtained using a Renishaw inVia Raman microscope in backscattering mode. The Raman excitation source is an all solid-state, single frequency laser emitting at $532 \mathrm{~nm}$. The laser power was limited to $1.8 \mathrm{~mW}$ at the sample to minimize sample heating. Scanning was accomplished using a stepping XYZ stage with a $1 \mu \mathrm{m}$ resolution. Scans of the $\mathrm{Si} / \mathrm{SiO}_{2}$ membrane were accomplished by focusing the laser through a microscope objective, resulting in a spatial resolution of $\sim 1 \mu \mathrm{m}$. Polarization was not used during the Raman stress measurements. The frequency shifts in the Raman spectra were found by fitting the Raman peak with a Lorentzian function with an error of approximately $0.1 \mathrm{Rcm}^{-1}$. The Raman shift was then referenced to the Rayleigh scattering line to account for any spectrometer variations.

Figure 10(a) shows an example 3D FEM mises stress image obtained from CoventorWare for the $\mathrm{Si} / \mathrm{SiO}_{2}$ membrane and identifies the stress magnitudes and locations across the membrane. The modeled membrane stress results indicate the peak stresses of approximately $340 \mathrm{MPa}$ are located primarily at peak deflection locations (i.e. near the center of the membrane). In addition, the image indicates the corners of the square membrane cause an increased stress reflected toward the center of the membrane. From this model, a circular membrane could reduce this reflected stress, mitigating these high stress locations; however, the deflection of the membrane is ultimately controlled by the membrane thickness and the stress magnitudes within the material layers. Figure $10(\mathrm{~b})$ is a comparison plot between the stress profile obtained from extracting a 2D stress profile from CoventorWare and a typical stress profile obtained from micro-Raman spectroscopy. As can be seen from Fig. 10(b), the micro-Raman stress profile compares favorably with the stress magnitudes and locations from the FEM model results. The micro-Raman spectroscopy stress profile also indicates peak stress near the center of the membrane and measured to be approximately $370 \mathrm{MPa}$. The stress profile shown in Fig. $10(\mathrm{~b})$ is similar to the uniform loaded fixed-fixed beam stress profile shown in Fig. $4(\mathrm{~b})$. The primary difference in the profiles are the stress and deflection magnitudes in the model as they only included a small uniformly distributed load which is extremely small when compared to the inherent forces due to the 
residual stresses. In addition, the FEM stress images for the $\mathrm{Si} / \mathrm{SiO}_{2}$ membrane with the Ti/Au metal layer are nearly identical to the image shown in Fig. 10(a) with the exception of the stress magnitudes resulting from the added metal layers. A micro-Raman spectroscopy stress profile cannot be obtained for the metal layer due to the high reflection of the gold layer. On a side note, significantly higher stress values applied to the silicon device layer resulted in only minimal changes in the membrane deflection. Thus, as stated, the oxide layer dominates the overall deflection magnitude for this $\mathrm{Si} / \mathrm{SiO}_{2}$ membrane.

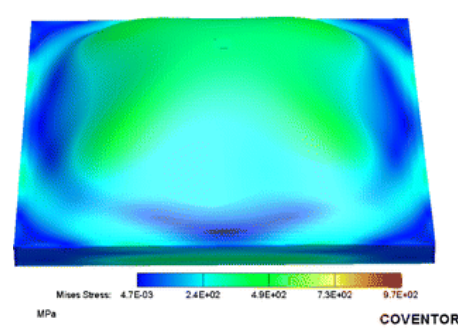

(a)

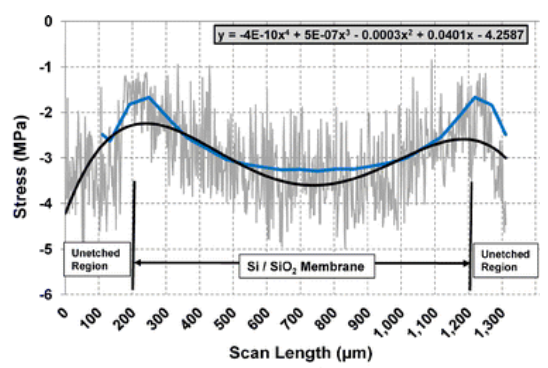

(b)

Fig. 10 (a) shows the Mises stress magnitudes and locations in the $\mathrm{Si} / \mathrm{SiO}_{2}$ membrane as modeled using CoventorWare, and $(\mathbf{b})$ a comparison of the stress profile obtained from CoventorWare to the residual stress profile obtained using micro-Raman spectroscopy for the $\mathrm{Si}_{/} \mathrm{SiO}_{2}$ membrane

\section{Load Deflection Testing}

All testing was performed on $1 \mathrm{~mm}^{2}$ fabricated membranes in which the buckled oxide membrane is an axially symmetric dome that resembles the geometry of Fig. $\underline{3(a)}$ if rotated around the $k_{2}$ spring. The load deflection plot obtained from a Si/SiO${ }_{2}$ membrane structure shown in Fig. 1 (b) was obtained and compared to the disk cone spring $\frac{1}{1}$ plot shown in Fig. 1 (a). The load deflection tests were performed utilizing a calibrated capacitive force sensor mounted to a piezo-electric actuator having a $20 \mu \mathrm{m}$ range with a resolution of $.4 \mu \mathrm{N}$ at $30 \mathrm{~Hz}$. The force sensor was displaced $200 \mathrm{~nm}$ at $500 \mathrm{~ms}$ intervals through the substrate into and away from the crown of the in-cavity deflected membrane. The produced membrane is on average $17 \mu \mathrm{m}$ lower than the surrounding device layer. The membrane is bistable in that it could either be pushed into or out of the substrate and retain its position. As illustrated in Fig. 1 (b), the load deflection plot consists of three regions of different rates. The first region demonstrates a "Hookean" linear spring return rate (positive spring constant), the second is a nearly zero spring return rate (constant force, a zero spring constant), and the third is a decreasing nonlinear spring return rate (negative spring constant). The load deflection curve shown in Fig. 1 (b) for the $\mathrm{Si} / \mathrm{SiO}_{2}$ membrane shape was typical of other structures with similar geometry except for the extended zero stiffness region around the inflection point. This plot gives a general idea of the largest returnable deflection that was achievable without pop through. In comparison of the plots shown in Fig. 1 , one immediately observes the similarities of the load deflection profiles for the two devices. The only real observable difference in the load profiles is that the large center disk spring results shown in Fig. 1(a) has load magnitudes in pounds and deflections in inches as compared to the micro load and nanometer deflections of the $\mathrm{Si} / \mathrm{SiO}_{2}$ membrane.

A second set of membranes were fabricated with the addition of thin film metallic layers (i.e. a $500 \AA \mathrm{Ti}$ and $3000 \AA$ gold) being evaporated onto the silicon device layer which resulted in a reduced peak membrane deflection to approximately $13.5 \mu \mathrm{m}$. The load deflection test was repeated for this multistacked membrane and the associated profile is shown in Fig. 11 along with the profile obtained for the $\mathrm{Si} / \mathrm{SiO}_{2}$ membrane for ease of comparison. As shown in Fig. 11, the $\mathrm{Si} / \mathrm{SiO}_{2}$ with metal profile 
demonstrates both a positive and negative linear stiffness where the inflection point is now much sharper and the negative stiffness portion has been highly linearized as compared to the $\mathrm{Si} / \mathrm{SiO}_{2}$ deflection profile. Curve fitting produces a spring constant of $-39 \mu \mathrm{n} / \mathrm{nm}(-390 \mathrm{~N} / \mathrm{m})$ over a $4 \mu \mathrm{m}$ deflection range in the negative portion. A linear negative spring constant with a range of over $3 \mu \mathrm{m}$ presents great possibilities. While improved sensitivity in accelerometers due to counteracting spring stiffness is an obvious use, ${ }^{47}$ the prospect of vibration isolation of MEMS sensors in general has great potential. $\underline{48,49}$

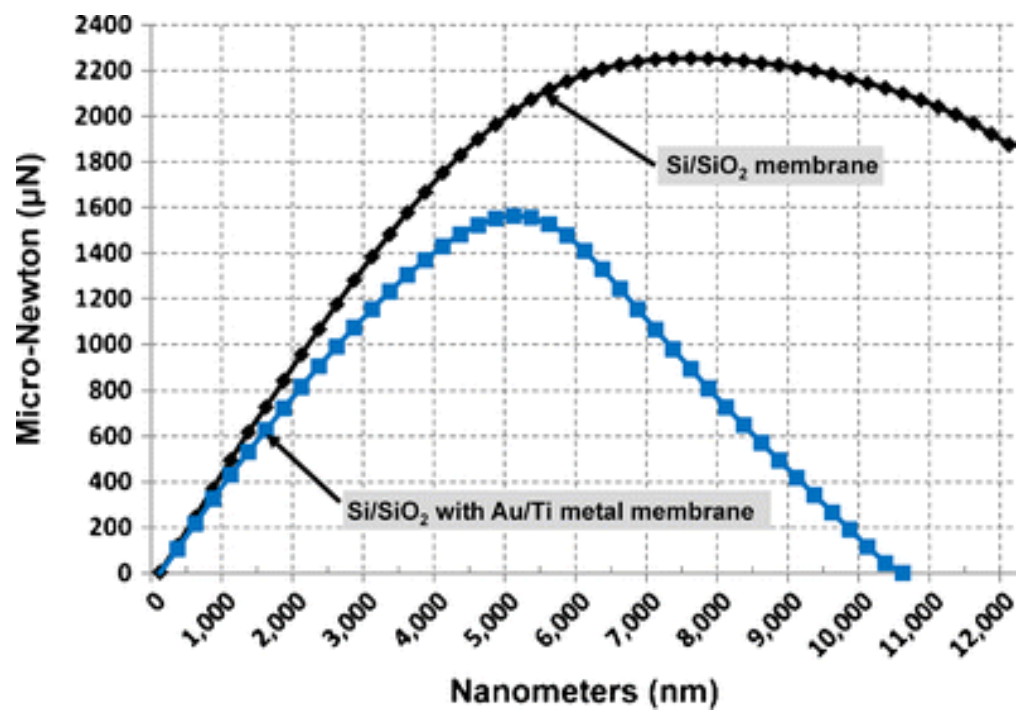

Fig. 11 Load deflection curves obtained for the $\mathrm{Si} / \mathrm{SiO}_{2}$ membrane, and the $\mathrm{Si} / \mathrm{SiO}_{2}$ membrane with a $500 \AA$ $\mathrm{Ti} / 3000 \AA$ A gold metal layer deposited on the membrane. As shown, the $\mathrm{Si} / \mathrm{SiO}_{2}$ membrane with metal provides a nearly linear positive and negative stiffness

\section{Conclusion}

Several different 16 element, $1 \mathrm{~mm}^{2}$ membranes ( $\mathrm{Si} / \mathrm{SiO}_{2}$ and $\mathrm{Si} / \mathrm{SiO}_{2}$ with $\mathrm{Ti} / \mathrm{Au}$ metal layers) were successfully modeled, fabricated and tested. Both the peak membrane deflection and inherent residual stress levels were modeled and experimentally measured with nearly identical results. An IFM was used to measure the membrane deflections for the $\mathrm{Si} / \mathrm{SiO}_{2}$ and $\mathrm{Si} / \mathrm{SiO}_{2}$ with $\mathrm{Ti} / \mathrm{Au}$ metal layers with deflections measuring approximately $17.0 \mu \mathrm{m}$ and $13.5 \mu \mathrm{m}$ respectively. The reduced deflection was expected through our CoventorWare FEM model results. The residual stress in the $\mathrm{Si} / \mathrm{SiO}_{2}$ membrane was measured using micro-Raman spectroscopy to be approximately $370 \mathrm{MPa}$. The stress profile obtained closely resembles the analytical stress profile generated for a fixed-fixed microbridge with a small uniform, distributed load. In addition, the measured peak stress levels in the membrane closely match the FEM results of $340 \mathrm{MPa}$. Lastly, a micro-Newton force sensor was used to produce the load verse deflection profiles for the membranes. The $\mathrm{Si} / \mathrm{SiO}_{2}$ membrane force testing results in a positive linear stiffness with an inflection point holding nearly constant with a slight negative stiffness. Force testing results for the $\mathrm{Si} / \mathrm{SiO}_{2}$ membrane with the added $\mathrm{Ti} / \mathrm{Au}$ metal layers results in both a linear positive and negative stiffness with a fairly sharp inflection point. 


\section{Notes}

\section{Acknowledgements}

The authors are thankful to Dr. Robert Fitch at the Air Force Research Laboratory, Sensors Directorate for his assistance with the DRIE fabrication process. In addition, to Jeff Baugher and Tom Edelmann for their assistance with device fabrication and data collection.

\section{References}

1. Almen JO, Laszlo A (1936) The uniform-section disk spring. Trans ASME 56:305-314

2. Sulfridge $M$, Saif T, Miller N, Meinhart M (2004) Nonlinear dynamic study of a bistable MEMS: model and experiment. J Microelectromech Syst 13:725-731

3. Joglekar MM, Pawaskar DN (2011) Closed-form empirical relations to predict the static pull-in parameters of electrostatically actuated microcantilevers having linear width variation. Microsys Technol 17:35-45

4. "How It Works." Minus K Technology. Web. (2010) $<$ http://www.minusk.com/content/technology/how-it-works passive vibration isolatior.html>

5. Guo ZY, Liu XS, Yang ZC, Shao QC, Lin LT, Xie H, Yan GZ (2010) Electrostatic isolation structure for linearity improvement of a lateral-axis tuning fork gyroscope, (MEMS). 2010 IEEE 23rd Int. Conf., 264-267

6. Baugher JP, Coutu RA Jr (2011) Micromechanical structure with stable linear positive and negative stiffness. Conf Proc Soc Exp Mech 4:137-143

7. Qiu J, Lang JH, Slocum AH (2001) A centrally-clamped parallel-beam bistable MEMS mechanism. The 14th IEEE International Conference on Micro Electro Mechanical Systems, MEMS 2001, 353356

8. Kaltsas G, Nassiopoulou AG, Siakavellas M, Anastassikis E (1998) Stress effect on suspended polycrystalline silicon membranes fabricated by micromachining of porous silicon. Sens Actuators A 68:429-434

9. Howe RT, Boser BE, Pisano AP (1996) Polysilicon integrated microsystems: technologies and applications. Sens Actuators A 56:167-177

10. Maier-Schneider D, Köprülülü A, Ballhausen Holm S, Obermeier E (1996) Elastic properties and microstructure of LPCVD polysilicon films. J Micromech Microeng 6:436-446

11. Morshed S, Baldwin KE, Zhou B, Prorok BC (2009) Modifying geometry to enhance the performance of microcantilever-based acoustic sensors. Sensor Lett 7:38-41

12. Morshed S, Prorok BC (2007) Tailoring beam mechanics towards enhancing detection of hazardous biological species. Exp Mech 47:405-415

13. Guiming Z, Libo Z, Zhuangde J, Shuming Y, Yulong Z, Enze H, Rahman-Hebibul, Ziaopo W, Zhigang $L$ (2011) Surface stress-induced deflection of a microcantilever with various widths and overall microcantilever sensitivity enhancement via geometry modification. J Phys D: Appl Phys 425402(44):1-11

14. Lakes RS, Lee T, Bersie A, Wang YC (2001) Extreme damping in composite materials with negative-stiffness inclusions. Nature 565-567

15. Wang YC, Lakes RS (2004) Extreme stiffness systems due to negative stiffness elements. Am J Phys 72:40-50 
16. Handtmann M, Aigner R, Meckes A, Wachutka GKM (2002) Sensitivity enhancement of MEMS inertial sensors using negative springs and active control. Sens Actuators 97-98:153-160

17. Shigley JE, Mischke CR, Budynas RG (2004) Mechanical engineering design, 7th edn. McGrawHill, New York

18. Maenaka K (2008) MEMS inertial sensors and their applications. INSS 2008, 5th Intnl Conf on Networked Sensing Systems, 71-73

19. Tabata O, Kawahata K, Sugiyama S, Igarashi I (1989) Mechanical property measurements of thin films using load-deflection of composite rectangular membranes. Sen Actuators 20:135-141

20. Pan JY, Lin P, Masech F, Senturia SD (1990) Werification of FEM analysis of load-deflection methods for measuring mechanical properties of thin films. Tech Dig IEEE Solid-State Sensors \& Actuators Workshop 1990, Hilton Head Island, SC, 70-73

21. Maier-Schneider D, Maibach J, Obermeier E (1995) A new analytical solution for the loaddeflection of square membranes. J Microelectromech Syst 4:238-241

22. Timoshenko S, Woinowsky-Krieger S (1959) Theory of plates and shells. McGraw-Hill, New York

23. Pilkey WD (1994) Formulas for stress, strain, and structural matrices. Wiley \& Sons

24. CoventorWare ${ }^{\circledR}$ User's Manual (2010) Coventor, Inc., 4000 Centregreen Way, Cary, NC

25. De Wolf I (1996) Micro-Raman Spectroscopy to study local mechanical stress in silicon integrated circuits. Semicond Sci Technol 11:139-154

26. Best SR (2005) Detection of residual stress in multi-crystalline silicon wafers using swept-sine frequency response data. Dissertation, University of South Florida, Tampa, Florida

27. Koester DA, Mahadevan R, Hardy B, Markus KW (1999) MUMPs' ${ }^{\mathrm{TM}}$ Design Handbook Rev. 5, Cronos Integrated Microsystems, 3021 Cornwallis Road, Research Triangle Park, NC

28. Zou Q, Li Z, Liu L (1995) New methods for measuring mechanical properties of thin films in micromachining: beam pull-in (VPI) method and long beam deflection (LBD) method. Sens Actuators A 48:137-143

29. Anastassakis E, Pinczuk A, Burstein E, Pollak FH, Cardona M (1970) Effect of static uniaxial stress on the Raman spectrum of silicon. Solid State Commun 8:133-138

30. Starman LA, Lott JA, Amer MS, Cowan WD, Busbee JD (2003) Stress characterization of MEMS microbridges by micro-Raman spectroscopy. Sens Actuators A 104:107-116

31. De Wolf I (1996) Micro-Raman spectroscopy to study local mechanical stress in silicon integrated circuits. Semicond Sci Technol 11:139-154

32. Siakavellas M, Anastassikis E, Koltsas G, Nassiopoulos AG (1998) Micro-Raman characterization of stress distribution within free standing mono- and poly-crystalline silicon membranes. Microelectron Eng 41(42):469-472

33. Talaat H, Negm S, Schaffer HE, Kaltsas G, Nassiopoulos AG (2000) Micro-Raman analysis of polysilicon membranes deposited on porous silicon channels. J Non-Crystalline Solids 266269:1345-1349

34. Wu X, Yu J, Ren T, Liu L (2007) Micro-Raman spectroscopy measurement of stress in silicon. Microelectron J 38:87-90

35. Anaya J, Prieto AC, Martinez O, Torres A, Martin-Martin A, Jimenez J, Rodriquez A, Sangrador J, Rodriquez T (2011) Si and $\mathrm{Si}_{x} \mathrm{Ge}_{1-x}$ NWs studied by Raman spectroscopy. Physica Status Solidi C 8:1307-1310

36. Gustafson PA, Haris SJ, O'Neill AE, Waas AM (2006) Measurement of biaxial stress states in silicon using micro-raman spectroscopy. J Appl Mech Trans ASME 73:745-751 
37. Kang Y, Qiu Y, Lei Z, Hu M (2005) An application of Raman spectroscopy on the measurement of residual stress in porous silicon. Opt Lasers Eng 43:847-855

38. Harris SJ, O'Neill AE, Yang W, Gustafson P, Boileau J, Weber WH, Majumdar B, Ghosh S (2004) Measurement of the state of stress in silicon with micro-Raman spectroscopy. J Appl Phys 96:7195-7201

39. Srikar VT, Swan AK, Ünlü MS, Goldberg BB, Spearing SM (2003) Micro-Raman measurement of bending stresses in micromachined silicon flexures. J Microelectromechanical Systems 12:779787

40. Abel MR, Wright TL, King WP, Graham S (2007) Thermal metrology of silicon microstructures using raman spectroscopy. IEEE Trans Components Packaging Technol 30:200-208

41. Jungchul L, Beechem T, Wright TL, Nelsonand BA, Graham S, King WP (2006) Electrical, thermal, and mechanical characterization of silicon microcantilever heaters. J Microelectromechanical Systems 15:1644-1655

42. Taniyama A, Hirai Y, Sugano K, Tabata O, Ikehara T, Tsuchiya T (2011) Local stress analysis of single crystalline silicon resonator using micro Raman spectroscopy, IEEE 24th Intnl Conf on MEMS, 449-452

43. Xue $C$, Zheng $L$, Zhang $W$, Zhang B, Jian A (2006) A dynamic stress analyzer for microelectromechanical systems (MEMS) based on Raman spectroscopy. J Raman Spectrosc

44. Pan X, Tan CW, Miao J, Kasim J, Shen Z, Xie E (2009) The stress analysis of Si MEMS devices by Micro-Raman technique. Thin Solid Films 517:4905-4908

45. De Wolf I, Kalicinski S, De Coster J, Oprims H (2009) Methods to measure mechanical properties of NEMS and MEMS: challenges and pitfalls. Material Research Society Symposium Proceedings, 1185

46. Miyatake T, Pezzotti G (2011) Tensor-resolved stress analysis in silicon MEMS device by polarized Raman spectroscopy. Phys Status Solidi A 208:1151-1158

47. Ya'akobovitz A, Krylov S (2010) Toward sensitivity enhancement of MEMS accelerometers using mechanical amplification mechanism. Sens J IEEE 10:1311-1319

48. Lee SH, Lee SW, Najafi K (2007) A generic environment-resistant packaging technology for MEMS. Solid-State Sens Act Microsys Conf, TRANS 2007 Intnl, 335-338

49. Dean R, Flowers G, Hodel S, MacAllister K, Horvath R, Matras A (2002) Vibration isolation of MEMS sensors for aerospace applications. Proc. of the IMAPS Int. Conf. \& Exhib. on Adv. Pack. \& Sys., $166-170$ 